\title{
The effect of the duration between urine culture and semirigid ureteroscopic on the rate of systemic inflammatory response syndrome postoperatively
}

\author{
Fatih Akkaş ${ }^{1}$, Emre Sam ${ }^{1}$, Ahmet Cinislioglu ${ }^{1}$, İbrahim Karabulut ${ }^{1}$, Fatih Kursat \\ Yilmazel $^{1}$, Ubeyd Sungur ${ }^{2}$, and Feyzi Arda Atar ${ }^{2}$ \\ ${ }^{1}$ Erzurum Training and Research Hospital \\ ${ }^{2}$ Istanbul Bakirkoy Dr Sadi Konuk Training and Research Hospital
}

February 8, 2021

\begin{abstract}
Purpose: The aim of this study is to analyze the preoperative and intraoperative factors that might induce systemic inflammatory response syndrome after semirigid ureteroscopic lithotripsy (SULL), and to evaluate the impact of duration between preoperative bladder urine culture (PBUC) and surgery on postoperative systemic inflammatory response syndrome (SIRS). Methods: A retrospective review was conducted including patients who underwent SULL in our center between January 2011 and June 2020. Prior to surgery, PBUC were obtained from all patients and postoperatively patients were observed for signs of SIRS. Univariable and multivariable binary logistic regression analysis were implemented to demonstrate the factors that predict SIRS postoperatively. Results: The entire study included a cohort of 572 patients. The rate of SIRS following SULL was $1.7 \%$. Predictive factors for SIRS were listed as stone volume, surgical time, and history of recurrent urinary tract infection. No significant difference was detected in terms of the duration between PBUC and SULL when comparing the SIRS group with the other group. Conclusion: The duration between PBUC and SULL is not an efficacious factor for SIRS. It may be useful to conduct prospective studies to enlighten this issues as endourologists deal with this duration dilemma often in daily practice. Keywords: Semirigid ureteroscopic lithotripsy, Systemic inflammatory response syndrome, Preoperative bladder urine culture
\end{abstract}

Title: The effect of the duration between urine culture and semirigid ureteroscopic on the rate of systemic inflammatory response syndrome postoperatively

Running head: The effect of duration of urine culture before operation on SIRS

Fatih Akkas ${ }^{1}$, Emre Sam ${ }^{1}$, Emre Cinislioglu ${ }^{1}$, Ibrahim Karabulut ${ }^{1}$, Fatih Kursat Yllmazel $^{1}$, Ubeyd Sunger $^{2}$, Yavuz Onur Danacioglu², Feyzi Arda Atar ${ }^{2}$

1 Department of Urology, University of Health Sciences, Erzurum Regional Training and Research Hospital, Erzurum, Turkey

2 Department of Urology, University of Health Sciences, Bakirkoy Dr. Sadi Konuk Training and Research Hospital, Istanbul, Turkey

Corresponding author: Fatih Akkas, MD: Department of Urology, University of Health Sciences, Erzurum Regional Training and Research Hospital, Erzurum, Turkey

Email: fatihakkas86@gmail.com

Corresponding address: Cat Yolu Street, 25400, Erzurum, Turkey 
Phone: 90(554)417 8861

Financial Disclosure: The authors declared that this study received no financial support.

Conflict of interest: The authors report no conflicts of interest

\section{Abstract}

Purpose: The aim of this study is to analyze the preoperative and intraoperative factors that might induce systemic inflammatory response syndrome after semirigid ureteroscopic lithotripsy (SULL), and to evaluate the impact of duration between preoperative bladder urine culture (PBUC) and surgery on postoperative systemic inflammatory response syndrome (SIRS).

Methods: A retrospective review was conducted including patients who underwent SULL in our center between January 2011 and June 2020. Prior to surgery, PBUC were obtained from all patients and postoperatively patients were observed for signs of SIRS. Univariable and multivariable binary logistic regression analysis were implemented to demonstrate the factors that predict SIRS postoperatively.

Results: The entire study included a cohort of 572 patients. The rate of SIRS following SULL was 1.7\%. Predictive factors for SIRS were listed as stone volume, surgical time, and history of recurrent urinary tract infection. No significant difference was detected in terms of the duration between PBUC and SULL when comparing the SIRS group with the other group.

Conclusion: The duration between PBUC and SULL is not an efficacious factor for SIRS. It may be useful to conduct prospective studies to enlighten this issues as endourologists deal with this duration dilemma often in daily practice.

Keywords : Semirigid ureteroscopic lithotripsy, Systemic inflammatory response syndrome, Preoperative bladder urine culture

\section{What's already known about this topic?}

Urinary tract infection after endourological stone treatment is a common complication. One of the main precautions is to capture sterile urine culture before the operation according to the guidelines; however, no comment was made regarding the timing of preoperative bladder urine culture (PBUC) before the surgery. In countries with a high rate of urinary system stone disease, waiting times are prolonged in stone surgeries such as semirigid ureteroscopic lithotripsy (SULL) in tertiary referral institutions. This causes an increase in the time between PBUC and SULL. In this study, we aimed to interrogate the preoperative and intraoperative factors that might cause systemic inflammatory responde syndrome (SIRS) in the early postoperative period and to investigate the effect of the time between PBUC and surgery on SIRS.

\section{What does this article add?}

In this study, we showed that prolongation of urine culture duration taken before SULL did not affect postoperative SIRS rates. On the other hand, we concluded that the outcome revealed in our study may be a result of the fact that factors such as stone burden, surgical time and history of recurrent UTI, identified in the literature as risk factors for infectious complications postoperatively, were observed more frequently in SIRS patients in comparison to patients with a normal postoperative period. The possible impact of the lengthening the waiting time in the study may have been obscured by these variables.

\section{Introduction}

In the latest European Association of Urology (EAU), a considerable significance is given to methods of endourological treatments as they are more commonly practiced in recent years(1). Semi-rigid ureteroscopic lithotripsy (SULL) is successfully performed in clinical practice. Though urinary tract infections ranging in clinical severity from fever to severe urosepsis are the most common complication after endourological stone surgery despite adequate perioperative antimicrobial prophylaxis $(2,3)$. As stated in EAU and American Urological Association (AUA) guidelines, preoperative bladder urine culture (PBUC) or urine microscopy 
should be taken before endourological treatment procedures; yet the timing of PBUC prior to surgery was not specified $(1,4)$.

In countries with a high prevalence of urinary tract stones, long waiting times for elective stone surgeries are evident in tertiary health care facilities. This lengthens the duration between PBUC and surgical procedures.

In this review, we aim to demonstrate the preoperative and intraoperative factors that may lead to systemic inflammatory response syndrome (SIRS) in the early postoperative period and to determine the impact of the time between PBUC and SULL on the incidence of SIRS.

\section{Material and Method}

A retrospective evaluation of the data from patients who had SULL between January 2011 and January 2020 for ureteral stones was performed. Patients who underwent SULL following insertion of a double J stent (DJS) or nephrostomy for decompression in obstructive uropathy due to urolithiasis were excluded from the study. The patient cohort with DJS prior to SULL were identified as those in whom DJSs were inserted for passive dilatation due to the inability to pass the ureteroscope into the target ureter in the first procedure. The clinical data from the second ureteroscopy (URS) was included. Furthermore, patients with positive preoperative PBUC results, patients who had SULL as an adjunctive treatment to simultaneous shock wave lithotripsy (SWL), and patients who underwent SULL as a diagnostic procedure were omitted from the review. Additionally, patients with conditions such as immunosuppression, diabetes, preoperative fever and renal failure were excluded from the study as they had a higher risk of developing sepsis.

Preoperatively, PBUC and whole blood analysis were obtained from all patients. Intravenous prophylactic antibiotics (cefazolin or fluoroquinolone) were given during the induction of anesthesia in patients with negative PBUC results prior to surgery. All patients were investigated preoperatively with intravenous urography or non-contrast spiral tomography.

A post-op review was conducted in the urology ward on the day following surgery. Body temperatures of $38^{\circ} \mathrm{C}$ and above were documented. The presence of two or more of the following was described as SIRS: temperature $>38{ }^{\circ} \mathrm{C}$ or $<36{ }^{\circ} \mathrm{C}$, heart rate $>90$ beats/minute, respiratory rate $>20 /$ minute, and white cell count $>12,000 / \mathrm{mm} 3$ or $<4000 / \mathrm{mm} 3$. From patients with fever or SIRS, blood cultures (BC) and PBUC were collected. The study only included the patients who fulfilled the SIRS criteria in the first week following the surgical procedure.

The study group was separated into two cohorts as the normal group and the SIRS group. A comparison between the groups was made evaluating the demographic characteristics, stone characteristics [number, diameter $(\mathrm{mm})$, volume ( $\mathrm{mm} 3)$, density (Hounsfield Unit)], duration of the surgery, length of hospital stay (LOS), presence of previous DJS, history of ipsilateral stone surgery (ISS), preoperative PBUC positivity, history of recurrent urinary tract infection (UTI) and length of time between PBUC and SULL. The recurrent UTI definition provided in the EAU guidelines as at least three UTIs/year or two UTIs in the last six months was used in the study (5).

All surgeries were performed in the lithotomy position under general anesthesia or spinal anaesthesia. An 8.0/ 9.8F Karl Storz semirigid ureteroscope was advanced through the ureter after the insertion of a 0.035inch polytetrafluoroethylene-coated guidewire (Boston Scientific, Marlborough, Massachusetts). A $200 \mu \mathrm{m}$ holmium-YAG laser (Lisa laser Sphinx, US) was used for performing laser lithotripsy. The stone fragmentation procedure was ceased when clinically insignificant residual fragments of less than $4 \mathrm{~mm}$ in diameter was achieved. In all cases of impacted stones, Double $\mathrm{J}$ stent $(4 \mathrm{~F}$ or $4.7 \mathrm{~F})$ was inserted. This decision was made by the endourologist in charge of the surgery on the basis of the operation time and the severity of the adjacent ureteral wall edema.

Kidney-ureter-bladder (KUB) radiography was carried out to evaluate the presence of residual stones on the first day following surgery. On postoperative day one following SULL, patients whose DJS position was verified to be normal by KUB radiography with no complications were discharged. An assessment was made at the postoperative first month for DJS removal and at the third postoperative month for review of 
residual stones with KUB radiography and urinary ultrasound or NCCT scan. A procedure was described as successful if stone-free on the third postoperative month.

Categorical variables are presented by providing numbers and percentages. Descriptive statistics (mean, standard deviation, minimum, median, maximum) are used to define continuous variables. The Shapiro-Wilk test was applied in order to determine if the distribution of continuous variables was natural. A comparison of the mean values of two different groups was made using the independent t-test sample or the MannWhitney U test. By utilizing Fisher's exact test, the percentages of the categorical variables were compared. When p-values were $<0.05$, statistical significance was considered. In an attempt to identify predictors of SIRS, univariable and multivariable binary logistic regression analyses were executed. Statistical analysis was performed using the Statistical Package for the Social Sciences version 21 software package (IBM SPSS Statistics; IBM Corp., Armonk, NY).

\section{Results}

Five hundred and seventy-two patients were included in our study. The patients' demographics and characteristics are presented in Table 1. The overall stone-free rate was $82.5 \%$. There were 10 patients (1.7\%) who met the criteria for SIRS; for the remainder of the patients, there were no infectious complications documented.

In SIRS group; mean stone volume, LOS, surgical time, and the rate of recurrent UTI history were significant. No statistical difference was observed in terms of the duration between PBUC and SULL between the normal groups and the SIRS groups (Table 2).

In relation to the time interval between PBUC and post-SULL SIRS, no statistically remarkable correlation was found (Table 3). To evaluate the cut off duration of surgical time for SIRS, the ROC curve analysis was performed. The cut off value for operation time in predicting post-SULL SIRS was 47.5 minutes (The AUC: 0.877; sensitivity $100 \%$; specificity $78.1 \%$; $95 \%$ CI: 0.835-0.920).

This study demonstrates the risk factors for SIRS postoperatively that were found significant in univariable analysis as presented in Table 3. In univariable analysis; stone volume, surgical period, LOS, and the history of recurrent UTI were detected as determinants of SIRS.

As we avoided using stone diameter and volume simultaneously in multivariable analysis, considering these variables strongly correlated with each other, this may lead to multicollinearity issues. LOS was another factor that was not studied in the multivariable analysis. In multivariable analysis, stone volume, operation time and the history of recurrent UTI were revealed as significant variables. (Table 3).

\section{Discussion}

SULL is an effective surgical method with high stone-free rate for treating ureteral stones, yet infectious complications are inevitable $(6,7)$. Infectious complications following URS may lead to an extended period of hospital stay with an impact on the prognosis of patients, increasing the potential risk for multiple organ dysfunction (7-9). As a result, it is important to prevent infection-related complications in order to minimize morbidity rates. In this review, the incidence of SIRS was $1.7 \%$ which is consistent with the rates stated in previous studies $(10-12)$.

There are several modifiable and non-modifiable factors mentioned in the literature that may be used as predictors of SIRS. Higher SIRS rates were correlated with larger stone burden, surgical time, infectious stone, irrigation with an increased flow rate, small-caliber UAS, URS preceding after obstructive pyelonephritis, a positive PBUC, and female sex $(7,8,13)$. Furthermore, history of previous urologic stone surgery, history of recurrent UTIs, preoperative pyuria, preoperative acute pyelonephritis, hydronephrosis, and the placement of a urethral catheter, DJS or percutaneous nephrostomy were recognized as factors increasing the risk for infectious complications in URS (14-17). In both univariable and multivariable analysis conducted in our study; stone burden, surgical time, and the history of recurrent UTI were statistically significant predictors for SIRS. 
Our research was not able to demonstrate the impact of factors in certain cases such as URS preceding obstructive pyelonephritis, acute pyelonephritis, and hydronephrosis due to the fact that all patients had stone surgery as elective cases. Compared with the non-SIRS group, the female sex rate in the SIRS group was higher, yet the difference was not statistically significant. The presence of DJS preoperatively was not identified as a predictive factor for SIRS in our study. We thought that the reason for this result might be that patients who were placed DJ stents due to obstructive uropathy were not included in the study. The only reason for having a DJS preoperatively was passive dilatation in our study. Additionally, this outcome may have occurred as the mean time period for DJS insertion to achieve passive dilatation was less than 21 days (18).

Stone cultures for prediction of infectious complications following PNL surgery and the management of postoperative antibiotic treatment were found to have an increased value in recent years (19-21). The current research revealed samples of preoperative bladder urine to be insufficient in identifying microorganisms surrounding the stone because the fragmented stone cultures were usually different from the stone surface or PBUC (22).

In contrary to previous studies, no association was shown between renal pelvic urine culture (RPUC), stone culture (SC) and sepsis or SIRS in the study by Koras et al.(23). The common message of all the studies, however, is that intraoperative cultures may be crucial for guidance on antibiotic treatment postoperatively. In a study exploring the association of RPUC and SC with SIRS following URS, it was stated that PBUC was incompatible with RPUC and SC (9). Reconsideration of the antibiotic therapy according to the results of the RPUC and SC was recommended in cases of postoperative infectious complications (9). Nevertheless, in the current study, 20 out of 23 patients with SIRS had PBUC, RPUC or SC growth, and PBUC, RPUC and SC were observed to be compatible in eight (40\%) patients. Furthermore, no growth was observed in RPUC and SC in five (25\%) patients, and only PBUC positivity was found; postoperative antibiotic treatment was adjusted according to the PBUC results. Since RPUC and SC may be considered as time-consuming tests, it is clear that the value of PBUC may never be underestimated. As we primarily aimed to assess the impact of the time between PBUC and RIRS on SIRS, evaluating the effect of the duration between PBUC and SULL more precisely, the positivity of PBUC was incorporated as a variable for predicting SIRS in the study.

In countries with a high prevalence of urinary system stone disease in tertiary referral institutions such as our clinic, waiting times are extended in elective stone surgeries such as SULL. This leads to an increase in the duration between PBUC and SULL. The lengthening of this time interval raises questions in the minds of both patients and doctors. Surgeons may become suspicious that as time increases, re-infections may occur in those patients with a risk of UTI. It was shown in our research that the time period between PBUC and SULL was not a predictive factor for SIRS. Extending the waiting time for SULL may increase the risk of complications caused by infection. The outcome revealed in our study may be a result of the fact that factors such as stone burden, surgical time and history of recurrent UTI, identified in the literature as risk factors for infectious complications postoperatively $(8,14,24)$, were observed more frequently in SIRS patients in comparison to patients with a normal postoperative period. The possible impact of the lengthening the waiting time in the study may have been obscured by these variables.

There are some limitations to our study. The operations were undertaken by urology specialists and residents. Thus, the parameters depending on the operator may be biased. The retrospective design was another limitation of our study. In addition, this study only reveals the experience of a single center.

\section{Conclusion}

This study reviews the effect of the waiting time for SULL, taking the lead on the matter in the literature. In conclusion, the duration between PBUC and SULL was not identified to be a variable that could predict SIRS. Prospective studies may be useful for clarifying this issue, frequently encountered by endourologists in daily practice.

\section{Financial Disclosure}


The authors declared that this study received no financial support.

\section{Conflict of interest}

The authors declare that they have no confict of interest.

\section{Ethical approval}

All procedures performed in studies involving human participants were in accordance with the ethical standards of the institutional and/or national research committee and with the 1964 Helsinki Declaration and its later amendments or comparable ethical standards. Because of the retrospective nature of the study, we did not admitted to the ethics committee of our institution.

\section{References}

1. Türk C, Neisius A, Petř́k A, et al. EAU Guidelines on Urolithiasis 2020.

2. Berardinelli F, De Francesco P, Marchioni M, et al. Infective complications after retrograde intrarenal surgery: a new standardized classification system. Int Urol Nephrol 2016; 48:1757-1762.

3. Ghosh A, Oliver R, Way C, et al. Results of day-case ureterorenoscopy (DC-URS) for stone disease: prospective outcomes over 4.5 years. World J Urol 2017; 35 : 1757-1764.

4. Preminger GM, Tiselius HG, Assimos DG, et al. 2007 Guideline for the Management of Ureteral Calculi. J Urol 2007; 178:2418-2434.

5. Grabe M, Bartoletti R, Bjerklund-Johansen TE, et al. EAU 2020 Guidelines on Urological Infections. Eur Assoc Urol 2020; 33-40.

6. Kim JW, Lee YJ, Chung JW, et al. Clinical characteristics of postoperative febrile urinary tract infections after ureteroscopic lithotripsy. Investig Clin Urol 2018; 59 :335-341.

7. Uchida Y, Takazawa R, Kitayama S, et al. Predictive risk factors for systemic inflammatory response syndrome following ureteroscopic laser lithotripsy. Urolithiasis 2018; $46: 375-381$.

8. Mi Q, Meng X, Meng L, et al. Risk Factors for Systemic Inflammatory Response Syndrome Induced by Flexible Ureteroscope Combined with Holmium Laser Lithotripsy. Biomed Res Int 2020; 6842479

9. Yoshida S, Takazawa R, Uchida Y, et al. The significance of intraoperative renal pelvic urine and stone cultures for patients at a high risk of post-ureteroscopy systemic inflammatory response syndrome. Urolithiasis 2019; $47: 533-540$.

10. Özsoy M, Acar O, Sarica K, et al. Impact of gender on success and complication rates after ureteroscopy. World J Urol 2015;33 : 1297-1302.

11. Elashry OM, Elgamasy AK, Sabaa MA, et al. Ureteroscopic management of lower ureteric calculi: A 15-year single-centre experience. BJU Int 2008; 102 : 1010-1017.

12. Martov A, Gravas S, Etemadian M, et al. Postoperative Infection Rates in Patients with a Negative Baseline Urine Culture Undergoing Ureteroscopic Stone Removal: A Matched Case-Control Analysis on Antibiotic Prophylaxis from the CROES URS Global Study. J Endourol 2015; 29 : 171-180.

13. Southern JB, Higgins AM, Young AJ, et al. Risk Factors for Postoperative Fever and Systemic Inflammatory Response Syndrome after Ureteroscopy for Stone Disease. J Endourol 2019; 33 : 516-522.

14. Moses RA, Ghali FM, Pais VM, et al. Unplanned Hospital Return for Infection following UreteroscopyCan We Identify Modifiable Risk Factors? J Urol 2016; 195 : 931-936.

15. Fan S, Gong B, Hao Z, et al. Risk factors of infectious complications following flexible ureteroscope with a holmium laser: A retrospective study. Int J Clin Exp Med 2015; 8 : 11252-11259. 
16. Mitsuzuka K, Nakano O, Takahashi N, et al. Identification of factors associated with postoperative febrile urinary tract infection after ureteroscopy for urinary stones. Urolithiasis 2016; 44:257-262.

17. Sohn DW, Kim SW, Hong CG, et al. Risk factors of infectious complication after ureteroscopic procedures of the upper urinary tract.J Infect Chemother 2013; 19 : 1102-1108.

18. Itami Y, Miyake M, Owari T, et al. Optimal timing of ureteroscopic lithotripsy after the initial drainage treatment and risk factors for postoperative febrile urinary tract infection in patients with obstructive pyelonephritis: a retrospective study. BMC Urol 2021;21 : 1-11.

19. Dogan HS, Guliyev F, Cetinkaya YS, et al. Importance of microbiological evaluation in management of infectious complications following percutaneous nephrolithotomy. Int Urol Nephrol 2007;39 : 737-742.

20. Gonen M, Turan H, Ozturk B, et al. Factors affecting fever following percutaneous nephrolithotomy: A prospective clinical study. J Endourol 2008; 22 : 2135-2138.

21. Chen Y, Liao B, Feng S, et al. Comparison of Safety and Efficacy in Preventing Postoperative Infectious Complications of a 14/16F Ureteral Access Sheath with a 12/14F Ureteral Access Sheath in Flexible Ureteroscopic Lithotripsy. J Endourol 2018; 32 : 923-927.

22. Doğan HS, Şahin A, Çetinkaya Y, et al. Antibiotic prophylaxis in percutaneous nephrolithotomy: Prospective study in 81 patients. J Endourol 2002; $16: 649-653$.

23. Koras O, Bozkurt IH, Yonguc T, et al. Risk factors for postoperative infectious complications following percutaneous nephrolithotomy: a prospective clinical study. Urolithiasis 2014; 43 : 55-60.

24. Chugh S, Pietropaolo A, Montanari E, Sarica K, Somani BK. Predictors of Urinary Infections and Urosepsis After Ureteroscopy for Stone Disease: a Systematic Review from EAU Section of Urolithiasis (EULIS).Curr Urol Rep 2020; $21: 16$

Table 1.Demographic data, stone characteristics, and clinical variables

Variables

Number of patients, $\mathrm{n}(\%)$

Mean age \pm SD, year

Mean $\mathrm{BMI} \pm \mathrm{SD}, \mathrm{kg} / \mathrm{m}^{2}$

Sex, $\mathrm{n}(\%)$ Male Female

ASA, n(\%) ASA 1 ASA 2 ASA 3

History of ipsilateral stone surgery, $\mathrm{n}(\%)$

Mean stone number $\pm \mathrm{SD}$

Mean stone diameter $\pm \mathrm{SD}, \mathrm{mm}$

Mean stone volume $\pm \mathrm{SD}, \mathrm{mm}^{3}$

Mean density $\pm \mathrm{SD}, \mathrm{HU}$

Preop DJS, n(\%)

Mean operation time $\pm \mathrm{SD}$, min.

Blood transfusion, $\mathrm{n}(\%)$

Mean $\operatorname{LOS} \pm \mathrm{SD}$, day

Preop recurren UTI, n(\%)

Stone free rate, $\mathrm{n}(\%)$

Mean duration between PBUC and SULL \pm SD, day

Postop SIRS, n(\%)
$57245.5 \pm 15.726 .9 \pm 3.3390(68.2) 182(31.8)$

208 (36.4) 304 (53.2) 59 (10.3) 186 (32.5) $1.09 \pm$

$0.3711 .2 \pm 4.7271 \pm 401000 \pm 32438$ (6.6) 63

(11.0) $41.6 \pm 10.30(0) 1.14 \pm 0.6851$ (8.9) 472

(82.5) $10.3 \pm 5.610(1.7)$ 
SD, standart deviation; BMI, body massindex; ASA, American Society of Anaesthesia; ISS, ipsilateral stone surgery; SWL, shock wave lithotripsy; HU, hounsfield unit; DJS, double J stent; LOS, lenght of stay; UTI, urinary tract infection; PBUC, preoperative bladder urine culture; SULL, semirigid ureteroscopic lithotripsy
SD, standart deviation; BMI, body massindex; ASA, American Society of Anaesthesia; ISS, ipsilateral stone surgery; SWL, shock wave lithotripsy; HU, hounsfield unit; DJS, double J stent; LOS, lenght of stay; UTI, urinary tract infection; PBUC, preoperative bladder urine culture; SULL, semirigid ureteroscopic lithotripsy

Table 2. Comparison of patients' characteristics according to SIRS

\begin{tabular}{|c|c|c|c|}
\hline Variables & Normal group & SIRS group & $P$ value \\
\hline Number of patients & 562 & 10 & \\
\hline Mean age $\pm S D$, year & $45.5 \pm 15.5$ & $43.6 \pm 24.5$ & $0.925++$ \\
\hline $\begin{array}{l}\text { Mean BMI } \pm \mathrm{SD} \\
\mathrm{kg} / \mathrm{m}^{2}\end{array}$ & $26.9 \pm 3.33$ & $26.8 \pm 2.11$ & $0.884+$ \\
\hline Gender(female), n(\%) & $178(31.7)$ & $4(40.0)$ & $0.733 \S$ \\
\hline $\begin{array}{l}\text { ASA score, } n(\%) \text { ASA1 } \\
\text { ASA } 2 \text { ASA } 3\end{array}$ & $\begin{array}{l}205(36.5) 299(53.3) 57 \\
(10.2)\end{array}$ & $3(30.0) 5(50.0) 2(20)$ & $0.452 \S$ \\
\hline History of ISS, n(\%) & $182(32.4)$ & $4(40.0)$ & $0.735 \S$ \\
\hline SWL history, $\mathrm{n}(\%)$ & $199(35.4)$ & $4(40.0)$ & $0.749 \S$ \\
\hline $\begin{array}{l}\text { Mean stone number } \pm \\
\text { SD }\end{array}$ & $1.09 \pm 0.36$ & $1.20 \pm 0.63$ & $0.376+$ \\
\hline $\begin{array}{l}\text { Mean stone diameter } \pm \\
\mathrm{SD}, \mathrm{mm}\end{array}$ & $11.2 \pm 4.72$ & $12.0 \pm 1.54$ & $0.705+$ \\
\hline $\begin{array}{l}\text { Mean stone volume } \pm \\
\mathrm{SD}, \mathrm{mm}^{3}\end{array}$ & $270 \pm 38.5$ & $356 \pm 44.5$ & $<0.001+$ \\
\hline Mean $\mathrm{HU} \pm \mathrm{SD}$ & $1000 \pm 324$ & $969 \pm 334$ & $0.760+$ \\
\hline Preop DJS, n(\%) & $61(10.9)$ & $2(20)$ & $0.303 \S$ \\
\hline $\begin{array}{l}\text { Mean operation time } \pm \\
\text { SD, min. }\end{array}$ & $41.4 \pm 10.2$ & $54.2 \pm 6.19$ & $<0.001+$ \\
\hline Mean LOS \pm SD, day & $1.09 \pm 0.40$ & $3.60 \pm 3.50$ & $<0.001++$ \\
\hline Postop DJS, n(\%) & $437(77.8)$ & $9(90.0)$ & $0.699 \S$ \\
\hline $\begin{array}{l}\text { Preop recurrent UTI, } \\
\mathrm{n}(\%)\end{array}$ & $47(8.4)$ & $4(40.0)$ & $0.008 \S$ \\
\hline Duration between & $10.2 \pm 5.59$ & $11.3 \pm 6.3$ & $0.574+$ \\
\hline
\end{tabular}


SD, standart deviation; BMI, body massindex;

ASA, American Society of Anaesthesia; ISS, ipsilateral stone surgery; SWL, shock wave lithotripsy; HU, hounsfield unit; DJS, double J stent; LOS, lenght of stay; UTI, urinary tract infection; PBUC, preoperative bladder urine culture; SULL, semirigid ureteroscopic lithotripsy + Independent Sample t test ++ Mann

Whitney u test §Fisher Exact test
SD, standart deviation; BMI, body massindex; ASA, American Society of Anaesthesia; ISS, ipsilateral stone surgery; SWL, shock wave lithotripsy; HU, hounsfield unit; DJS, double J stent; LOS, lenght of stay; UTI, urinary tract infection; PBUC, preoperative bladder urine culture; SULL, semirigid ureteroscopic lithotripsy + Independent Sample t test ++ Mann

Whitney u test §Fisher Exact test
SD, standart deviation; BMI, body massindex; ASA, American Society of Anaesthesia; ISS, ipsilateral stone surgery; SWL, shock wave lithotripsy; HU, hounsfield unit; DJS, double J stent; LOS, lenght of stay; UTI, urinary tract infection; PBUC, preoperative bladder urine culture; SULL, semirigid ureteroscopic lithotripsy + Independent Sample t test ++ Mann Whitney u test §Fisher Exact test
SD, standart deviation; BMI, body massindex; ASA, American Society of Anaesthesia; ISS, ipsilateral stone surgery; SWL, shock wave lithotripsy; HU, hounsfield unit; DJS, double J stent; LOS, lenght of stay; UTI, urinary tract infection; PBUC, preoperative bladder urine culture; SULL, semirigid ureteroscopic lithotripsy + Independent Sample t test ++ Mann Whitney u test $\S$ Fisher Exact test

Table 3. The association between the duration of PBUC and SULL and postoperative SIRS

Sperman's rho*

Post-SULL SIRS

$\mathrm{CC}$

CC, correlation coefficient; SULL, semirigid ureteroscopic lithotripsy; PBUC, preoperative bladder urine culture

Sig. $\left(2-t_{\text {. }}\right.$

$\mathrm{CC}$, corr

Table 4: To predict SIRS, univariable and multivariable analysis were applied

\begin{tabular}{|c|c|c|c|c|c|c|c|}
\hline & Univariable & Univariable & Univariable & Univariable & Multivariable & Multivariable & Multivariable \\
\hline Variables & OR & $95 \% \mathrm{CI}$ & $95 \% \mathrm{CI}$ & $p$ & OR & $95 \% \mathrm{CI}$ & $p$ \\
\hline Age & 0.992 & $\begin{array}{l}0.953- \\
1.033\end{array}$ & 0.693 & 0.693 & & & \\
\hline BMI & 0.986 & $\begin{array}{l}0.814- \\
1.193\end{array}$ & 0.883 & 0.883 & & & \\
\hline $\begin{array}{l}\text { Gender } \\
\text { (female) }\end{array}$ & 1.438 & $\begin{array}{l}0.401- \\
5.160\end{array}$ & 0.577 & 0.577 & & & \\
\hline ASA3 & 0.477 & $\begin{array}{l}0.090- \\
2.517\end{array}$ & 0.383 & 0.383 & & & \\
\hline $\begin{array}{l}\text { History of } \\
\text { ISS }\end{array}$ & 0.718 & $\begin{array}{l}0.200- \\
2.577\end{array}$ & 0.612 & 0.612 & & & \\
\hline $\begin{array}{l}\text { History of } \\
\text { SWL }\end{array}$ & 1.216 & $\begin{array}{l}0.339- \\
4.360\end{array}$ & 0.764 & 0.764 & & & \\
\hline $\begin{array}{l}\text { Stone } \\
\text { number }\end{array}$ & 1.672 & $\begin{array}{l}0.520- \\
5.378\end{array}$ & 0.389 & 0.389 & & & \\
\hline $\begin{array}{l}\text { Stone } \\
\text { diameter } \\
\text { Stone } \\
\text { volume }\end{array}$ & 1.0321 .033 & $\begin{array}{l}0.879-1.211 \\
1.019-1.046\end{array}$ & $0.705<0.001$ & $0.705<0.001$ & 1.046 & $1.026-1.065$ & $<0.001$ \\
\hline
\end{tabular}




\begin{tabular}{|c|c|c|c|c|c|c|c|}
\hline & Univariable & Univariable & Univariable & Univariable & Multivariable & Multivariable & $\overline{\text { Multivariable }}$ \\
\hline $\mathrm{HU}$ & 1.000 & $\begin{array}{l}0.998- \\
1.002\end{array}$ & 0.759 & 0.759 & & & \\
\hline $\begin{array}{l}\text { Preop } \\
\text { DJS }\end{array}$ & 0.499 & $\begin{array}{l}0.127- \\
1.963\end{array}$ & 0.320 & 0.320 & & & \\
\hline $\begin{array}{l}\text { Operation } \\
\text { time }\end{array}$ & 1.080 & $\begin{array}{l}1.036- \\
1.127\end{array}$ & $<0.001$ & $<0.001$ & 1.172 & $\begin{array}{l}1.086- \\
1.265\end{array}$ & $<0.001$ \\
\hline LOS & 4.286 & $2.170-$ & $<0.001$ & $<0.001$ & & & \\
\hline $\begin{array}{l}\text { Postop } \\
\text { DJS }\end{array}$ & 2.574 & $\begin{array}{l}8.466 \\
0.323- \\
20.514\end{array}$ & 0.372 & 0.372 & & & \\
\hline $\begin{array}{l}\text { Preop } \\
\text { recurrent } \\
\text { UTI }\end{array}$ & 7.305 & $\begin{array}{l}1.991- \\
26.802\end{array}$ & 0.003 & 0.003 & 0.029 & $\begin{array}{l}0.003- \\
0.263\end{array}$ & 0.002 \\
\hline $\begin{array}{l}\text { Duration } \\
\text { between } \\
\text { PBUC } \\
\text { and SULL }\end{array}$ & 1.031 & $\begin{array}{l}0.926- \\
1.149\end{array}$ & 0.573 & 0.573 & & & \\
\hline
\end{tabular}




\begin{tabular}{|c|c|c|c|c|c|c|c|}
\hline & Univariable & Univariable & Univariable & Univariable & Multivariable & Multivariable & Multivariable \\
\hline $\mathrm{SD}$ & SD, & $\mathrm{SD}$ & SD, & SD, & SD, & SD, & SD, \\
\hline standart & standart & standart & standart & standart & standart & standart & standart \\
\hline deviation; & deviation; & deviation; & deviation; & deviation; & deviation; & deviation; & deviation; \\
\hline BMI, & BMI, & BMI, & BMI, & BMI, & BMI, & BMI, & BMI, \\
\hline body & body & body & body & body & body & body & body \\
\hline massin- & massin- & massin- & massin- & massin- & massin- & massin- & massin- \\
\hline dex; ASA, & dex; ASA, & dex; ASA, & dex; ASA, & dex; ASA, & dex; ASA, & dex; ASA, & dex; ASA, \\
\hline American & American & American & American & American & American & American & American \\
\hline Society of & Society of & Society of & Society of & Society of & Society of & Society of & Society of \\
\hline Anaesthe- & Anaesthe- & Anaesthe- & Anaesthe- & Anaesthe- & Anaesthe- & Anaesthe- & Anaesthe- \\
\hline sia; ISS, & sia; ISS, & sia; ISS, & sia; ISS, & sia; ISS, & sia; ISS, & sia; ISS, & sia; ISS, \\
\hline $\begin{array}{l}\text { ipsilateral } \\
\text { stone }\end{array}$ & $\begin{array}{l}\text { ipsilateral } \\
\text { stone }\end{array}$ & $\begin{array}{l}\text { ipsilateral } \\
\text { stone }\end{array}$ & $\begin{array}{l}\text { ipsilateral } \\
\text { stone }\end{array}$ & $\begin{array}{l}\text { ipsilateral } \\
\text { stone }\end{array}$ & $\begin{array}{l}\text { ipsilateral } \\
\text { stone }\end{array}$ & $\begin{array}{l}\text { ipsilateral } \\
\text { stone }\end{array}$ & $\begin{array}{l}\text { ipsilateral } \\
\text { stone }\end{array}$ \\
\hline surgery; & surgery; & surgery; & surgery; & surgery; & surgery; & surgery; & surgery; \\
\hline SWL, & SWL, & SWL, & SWL, & SWL, & SWL, & SWL, & SWL, \\
\hline shock & shock & shock & shock & shock & shock & shock & shock \\
\hline wave & wave & wave & wave & wave & wave & wave & wave \\
\hline lithotripsy; & lithotripsy; & lithotripsy; & lithotripsy; & lithotripsy; & lithotripsy; & lithotripsy; & lithotripsy; \\
\hline $\mathrm{HU}$ & HU, & HU, & HU, & HU, & $\mathrm{HU}$ & HU, & $\mathrm{HU}$ \\
\hline hounsfield & hounsfield & hounsfield & hounsfield & hounsfield & hounsfield & hounsfield & hounsfield \\
\hline unit; DJS, & unit; DJS, & unit; DJS, & unit; DJS, & unit; DJS, & unit; DJS, & unit; DJS, & unit; DJS, \\
\hline double J & double J & double J & double J & double J & double J & double J & double J \\
\hline stent; & stent; & stent; & stent; & stent; & stent; & stent; & stent; \\
\hline LOS, & LOS, & LOS, & LOS, & LOS, & LOS, & LOS, & LOS, \\
\hline lenght of & lenght of & lenght of & lenght of & lenght of & lenght of & lenght of & lenght of \\
\hline $\begin{array}{l}\text { stay; UTI, } \\
\text { urinary }\end{array}$ & $\begin{array}{l}\text { stay; UTI, } \\
\text { urinary }\end{array}$ & $\begin{array}{l}\text { stay; UTI, } \\
\text { urinary }\end{array}$ & $\begin{array}{l}\text { stay; UTI, } \\
\text { urinary }\end{array}$ & $\begin{array}{l}\text { stay; UTI, } \\
\text { urinary }\end{array}$ & $\begin{array}{l}\text { stay; UTI, } \\
\text { urinary }\end{array}$ & $\begin{array}{l}\text { stay; UTI, } \\
\text { urinary }\end{array}$ & stay; UTI, \\
\hline tract & tract & tract & tract & tract & tract & tract & tract \\
\hline infection; & infection; & infection; & infection; & infection; & infection; & infection; & infection; \\
\hline PBUC, & PBUC, & PBUC, & PBUC, & PBUC, & PBUC, & PBUC, & PBUC, \\
\hline $\begin{array}{l}\text { preopera- } \\
\text { tive }\end{array}$ & $\begin{array}{l}\text { preopera- } \\
\text { tive }\end{array}$ & $\begin{array}{l}\text { preopera- } \\
\text { tive }\end{array}$ & $\begin{array}{l}\text { preopera- } \\
\text { tive }\end{array}$ & $\begin{array}{l}\text { preopera- } \\
\text { tive }\end{array}$ & $\begin{array}{l}\text { preopera- } \\
\text { tive }\end{array}$ & $\begin{array}{l}\text { preopera- } \\
\text { tive }\end{array}$ & $\begin{array}{l}\text { preopera- } \\
\text { tive }\end{array}$ \\
\hline bladder & bladder & bladder & bladder & bladder & bladder & bladder & bladder \\
\hline urine & urine & urine & urine & urine & urine & urine & urine \\
\hline culture; & culture; & culture; & culture; & culture; & culture; & culture; & culture; \\
\hline SULL, & SULL, & SULL, & SULL, & SULL, & SULL, & SULL, & SULL, \\
\hline semirigid & semirigid & semirigid & semirigid & semirigid & semirigid & semirigid & semirigid \\
\hline uretero- & uretero- & uretero- & uretero- & uretero- & uretero- & uretero- & uretero- \\
\hline scopic & scopic & scopic & scopic & scopic & scopic & scopic & scopic \\
\hline lithotripsy & lithotripsy & lithotripsy & lithotripsy & lithotripsy & lithotripsy & lithotripsy & lithotripsy \\
\hline
\end{tabular}

